\title{
Fluorescent Pseudomonas Strains with only Few Plant-Beneficial Properties Are Favored in the Maize Rhizosphere
}

\author{
Jordan Vacheron 1,2,3,4, Yvan Moënne-Loccoz ${ }^{1,2,3,4}$, Audrey Dubost ${ }^{1,2,3,4}$, \\ Maximilien Gonçalves-Martins ${ }^{1,2,3,4}$, Daniel Muller ${ }^{1,2,3,4}$ and Claire Prigent-Combaret ${ }^{1,2,3,4 *}$ \\ ${ }^{1}$ Université de Lyon, Lyon, France, ${ }^{2}$ Université Lyon 1, Villeurbanne, France, ${ }^{3} \mathrm{CNRS}$, UMR5557, Ecologie Microbienne, \\ Villeurbanne, France, ${ }^{4}$ INRA, UMR1418, Villeurbanne, France
}

Plant Growth-Promoting Rhizobacteria (PGPR) enhance plant health and growth using a variety of traits. Effective PGPR strains typically exhibit multiple plant-beneficial properties, but whether they are better adapted to the rhizosphere than PGPR strains with fewer plant-beneficial properties is unknown. Here, we tested the hypothesis that strains with higher numbers of plant-beneficial properties would be preferentially

OPEN ACCESS

Edited by:

Benjamin Gourion, Laboratoire des Interactions Plantes-Microorganismes CNRS/INRA, France

Reviewed by:

Claudia Knief,

University of Bonn, Germany

Lei Zhang,

Washington State University, USA

*Correspondence:

Claire Prigent-Combaret claire.prigent-combaret@univ-lyon1.fr

Specialty section:

This article was submitted to

Plant Biotic Interactions,

a section of the journal

Frontiers in Plant Science

Received: 31 May 2016

Accepted: 29 July 2016

Published: 25 August 2016

Citation:

Vacheron J, Moënne-Loccoz Y, Dubost A, Gonçalves-Martins $M$, Muller $D$ and Prigent-Combaret $C$

(2016) Fluorescent Pseudomonas Strains with only Few Plant-Beneficial

Properties Are Favored in the Maize Rhizosphere. Front. Plant Sci. 7:1212.

doi: 10.3389/fpls.2016.01212 selected by plant roots. To this end, the co-occurrence of 18 properties involved in enhanced plant nutrition, plant hormone modulation, or pathogen inhibition was analyzed by molecular and biochemical methods in a collection of maize rhizosphere and bulk soil isolates of fluorescent Pseudomonas. Twelve plant-beneficial properties were found among the 698 isolates. Contrarily to expectation, maize preferentially selected pseudomonads with low numbers of plant-beneficial properties (up to five). This selection was not due to the predominance of strains with specific assortments of these properties, or with specific taxonomic status. Therefore, the occurrence of only few plant-beneficial properties appeared favorable for root colonization by pseudomonads.

Keywords: fluorescent Pseudomonas, PGPR, maize, functional groups, plant-beneficial properties

\section{INTRODUCTION}

Plant roots interact with huge amounts of soil microorganisms, constituting their rhizomicrobiota, which participate to optimal plant development in response to environmental conditions. Among the rhizomicrobiota, certain bacterial strains, called Plant-Growth Promoting Rhizobacteria PGPR, may exert beneficial effects on plant growth, development and/or health (Richardson et al., 2009; Vacheron et al., 2013). This entails various modes of action, related to improved nutrient supply (associative nitrogen fixation, phosphate solubilization, etc.), modulation of plant hormonal balance (via production of auxins, cytokinins, nitric oxide (NO), etc., or deamination of 1-aminocyclopropane-1-carboxylic acid (ACC)), and enhanced plant defense against parasites (through induction of systemic resistance pathways, or production of antimicrobial secondary metabolites, extracellular lytic enzymes, or surfactants; Spaepen et al., 2009; Vacheron et al., 2015).

It is not unusual that a given PGPR strain displays several different plant-beneficial properties (Loper et al., 2012; Bruto et al., 2014), which is thought to provide higher positive effects on the plant (Bashan and de-Bashan, 2010). This is expected to take place because (i) the effects of different 
modes of action may add-up quantitatively, or (ii) it could ensure that at least one mode of action is expressed in particular environmental conditions. Indeed, the most effective PGPR are typically multi-function strains (Rana et al., 2011; Almario et al., 2014a). In line with this, the loss of one mode of action often reduces plant-beneficial effects (Thomashow and Weller, 1988; Keel et al., 1990) while the gain of one may enhance plantbeneficial effects (Wang et al., 2000; Bakker et al., 2002; Holguin and Glick, 2003; Baudoin et al., 2010), and the combined use of PGPR strains with different modes of action can also improve the effects on the plant (Dunne et al., 1998; Combes-Meynet et al., 2011; Walker et al., 2012). Since strains with multiple plantbeneficial properties can provide higher benefits to the host, they might be more prevalent in the rhizosphere than related PGPR strains displaying a smaller number of plant-beneficial properties. This situation is reminiscent of the accumulation of virulence factors in pathogens, which allows a better fitness and host infection (Friesen et al., 2006). However, this hypothesis remains to be tested. Therefore, the objective of the present study was to assess whether the rhizosphere preferentially selects bacteria with high numbers of plant-beneficial properties.

To this end, we compared in various soils the effect of maize on the functional diversity of root-selected fluorescent Pseudomonas spp., a taxonomic group that displays a wide range of plant-beneficial properties and contains PGPR strains capable of phytostimulation and phytoprotection (Ahmad et al., 2008; Naik et al., 2008a,b; Loper et al., 2012; Rameshkumar et al., 2012; Sarma et al., 2014; Yadav et al., 2014). Plantbeneficial properties documented in these bacteria include associative nitrogen fixation (genes nif; Mirza et al., 2006), phosphate solubilization (Meyer et al., 2010), synthesis of the antimicrobial compound and root-branching signal 2,4diacetylphloroglucinol (DAPG - genes phl; Keel et al., 1990; Leij et al., 2002; Brazelton et al., 2008), synthesis of the auxinic phytohormone indole-3-acetic acid (IAA; Oberhänsli et al., 1991) and the cytokinins isopentenyl adenosine and trans-zeatin ribose (García de Salamone et al., 2001), synthesis of the plant signal nitric oxide (nitrite reductase gene nirS or nirK; Arese et al., 2003; Baudouin and Hancock, 2014), and deamination of the plant's ethylene precursor ACC (Glick et al., 1998; PrigentCombaret et al., 2008). Synthesis of pyrrolnitrin, pyoluteorin (de Souza and Raaijmakers, 2003), phenazine (Mavrodi et al., 2006), hydrogen cyanide (HCN; Frapolli et al., 2012), and the production of extracellular lytic enzymes such as chitinases and proteases (Sarma et al., 2014) are also often reported as Pseudomonas plant-beneficial properties involved in biocontrol. Numerous fluorescent Pseudomonas strains were isolated from disease-conducive and -suppressive soils (including the MS8 soil used in the present study), and characterized merely according to the biocontrol properties they harbored (Ramette et al., 2003, 2006; Frapolli et al., 2008; Almario et al., 2014b). Here, a collection of fluorescent Pseudomonas isolates was established and screened for the presence of a wider range of well-described plant-beneficial properties, using established and novel methods targeting relevant genes, enzymatic activities and/or compounds. This isolate library was used to address the question whether fluorescent pseudomonads harboring a high number of co-occurring plant-beneficial properties are preferably selected in the maize rhizosphere.

\section{MATERIALS AND METHODS}

\section{Soils}

Four soils were collected in October 2012 (Supplementary Table S1): MS8 from Morens, county Fribourg, Switzerland ( $46^{\circ} 52^{\prime}$ $04.77^{\prime \prime} \mathrm{N}$ and $6^{\circ} 54^{\prime} 15.83^{\prime \prime}$ E; Kyselková et al., 2009), Bmo1 from Béligneux, Ain, France ( $45^{\circ} 52^{\prime} 22.28^{\prime \prime} \mathrm{N}$ and $\left.5^{\circ} 7^{\prime} 53.21^{\prime \prime} \mathrm{E}\right), \mathrm{Ysa} 5$ and Ysa8 from Seyssel, Savoie region, France (respectively, $45^{\circ}$ $57^{\prime} 2.42^{\prime \prime} \mathrm{N}$ and $5^{\circ} 51^{\prime} 11.44^{\prime \prime} \mathrm{E}$; Almario et al., 2013), and $45^{\circ}$ $58^{\prime} 30.42^{\prime \prime} \mathrm{N}$ and $5^{\circ} 51^{\prime} 2.43^{\prime \prime} \mathrm{E}$ ). MS8 and Bmol have a morainic origin whereas Ysa5 and Ysa8 developed on sandstone material. Bmo1 and Ysa5 were cultivated with maize for at least 3 years, MS8 was an artificial meadow for at least 2 years, and Ysa8 is a natural grassland. Soils were taken from 10 to $30 \mathrm{~cm}$ depth at three locations 5-10 $\mathrm{m}$ apart in each field, and were sieved at $0.5 \mathrm{~mm}$.

\section{Plant Experiment}

Seeds of hybrid maize cultivar DK315 (Monsanto SAS/Dekalb, USA) and PR37Y15 (Pioneer Semences SAS, France) were surface-sterilized by soaking $1 \mathrm{~h}$ in sodium hypochlorite and one wash in $70 \%$ ethanol, and were rinsed three times with sterile distilled water. Three seeds of each maize variety were sown each in $2-\mathrm{dm}^{3}$ pots ( $2 \mathrm{~kg}$ fresh soil/pot; 3 pots/cultivar/soil) and soil water content was maintained at $20 \% \mathrm{w} / \mathrm{w}$. Unplanted pots ( 1 pot/soil) served as controls for sampling bulk soils. 21 days after sowing, rhizosphere soils and bulk soils were sampled (i.e., 3 rootadhering soils $\times 2$ cultivars $\times 4$ soils and 4 bulk soils). The root systems were shaken vigorously and rhizosphere extracts were prepared by putting each root system with adhering soil in $20 \mathrm{~mL}$ of $0.9 \% \mathrm{NaCl}$ solution and shaking $1 \mathrm{~h}$ at $150 \mathrm{rpm}$. Four bulk soil extracts were obtained using $10 \mathrm{~g}$ soil (in $20 \mathrm{~mL}$ ).

\section{Isolation and Characterization of Pseudomonas Isolates}

For isolation of fluorescent Pseudomonas, the 24 rhizosphere and four bulk soil extracts were serially diluted and $20 \mu \mathrm{L}$ was mixed with $180 \mu \mathrm{L}$ of King's B ${ }^{+++}$[i.e., King's B supplemented with ampicillin (40 mg/mL), chloramphenicol (13 mg/mL); Simon and Ridge, 1974; Landa et al., 2002; Latz et al., 2016] in 96well microtiter plate following a most probable number (MPN) design with eight wells per dilution. Aliquots from each last positive well were plated on King's $\mathrm{B}^{+++}$agar. At least 55 isolates were randomly selected for each of the 12 conditions [i.e., 4 soils $\times(2$ cultivars and bulk soil $)$ ] and all colonies were purified three times successively, giving a total of 698 isolates. Genomic DNA was extracted for all isolates using NucleoSpin ${ }^{\circledR}$ 96 Tissue kits (Ref - 740454.4; Macherey Nagel, Germany) and identification performed by sequencing the housekeeping gene rpoD (accession numbers LN885567 to LN886065, EMBL-EBI database) using primers rpoDf/rpoDr targeting the $r p o D$ alleles of bacteria from the P. fluorescens group (Frapolli et al., 2007). 
When $r p o D$ amplification failed, the 16SrRNA encoding rrs gene was amplified with $\mathrm{pA} / \mathrm{pH}$ (Edwards et al., 1989) and sequenced (accession numbers: LN885368 to LN885566, EMBLEBI database). rpoD sequences were aligned with MUSCLE (Edgar, 2004). Sequences were manually filtered to discard gaps and aligned regions of low quality. The phylogenetic trees were inferred with PHYML (Guindon et al., 2010) with the GTR model and 500 bootstraps. Isolate redundancy was estimated at $30 \%$, according to both $r p o D$ sequence similarity and functional profiles obtained.

\section{Screening of Pseudomonas Isolates for Plant-Beneficial Properties}

A total of 18 plant-beneficial properties were targeted. Molecular screening for plant-beneficial properties was performed by PCR targeting genes involved in production of 2,4 diacetylphloroglucinol ( $p h l D)$, pyrrolnitrin $(p r n D)$, pyoluteorin $(p l t C)$, phenazines (overlapping region of $p h z C / p h z D)$ and NO (nirS in pseudomonads), as well as ACC deamination (acdS) and nitrogen fixation (nifH). All amplifications were performed with a thermocycler Mastercycler (Eppendorf, Germany). The reaction volumes contained $10 \mathrm{x}$ PCR buffer, $50 \mathrm{mM} \mathrm{MgCl}_{2}$, $2 \mathrm{mM}$ dNTP, 5\% DMSO, $10 \mu \mathrm{M}$ of each primer (Supplementary Table S2), 1 unit of Taq polymerase (Invitrogen, Cergy-Pontoise, France) and $50 \mathrm{ng}$ of DNA. Several amplified fragments were sequenced and data blasted against the NCBI database in order to ascertain that isolates actually harbored the corresponding genes (accession numbers LT607759 to LT607801, EMBL-EBI database). No false-positive PCR results were found.

Screening for isolates with phosphate solubilizing activity was done by measuring the degradation halo on a National Botanical Research Institute's Phosphate (NBRIP) agar after 6 days at $28^{\circ} \mathrm{C}$, according to (Meyer et al., 2011). HCN production (indicated by color orange to red) was assessed after growth ( 3 days at $28^{\circ} \mathrm{C}$ ) on King's $\mathrm{B}^{++}+$agar, using a Whatman filter paper $\mathrm{n}^{\circ} 1$ previously soaked in $2 \%$ sodium carbonate in $0.5 \%$ picric acid solution and placed in the lid of the Petri dish (subsequently sealed with parafilm). Production of extracellular protease and chitinase was assessed using, respectively, milk agar and minimum medium supplemented with colloidal chitin (Kim et al., 2003).

An Ultra High Performance Liquid Chromatography (UHPLC) method was developed in order to screen isolates for production of the two auxinic phytohormones indole-3-acetic acid (IAA) and indol-3-butyric acid and the five cytokinin phytohormones trans-zeatin, trans-zeatin riboside, kinetin, 6-benzylaminopurine and isopentenyl adenosine. Briefly, all isolates were grown in $2 \mathrm{~mL}$ of King's B medium supplemented with $250 \mathrm{mM}$ of auxin precursor tryptophan and $0.1 \mathrm{mM}$ of cytokinin precursor adenine $\left(2\right.$ days at $\left.28^{\circ} \mathrm{C}, 300 \mathrm{rpm}\right)$. The cultures were centrifuged at $4500 \mathrm{rpm}$ during $8 \mathrm{~min}$ and filtered at $0.2 \mu \mathrm{m}$. Supernatants were subjected to UHPLC separation on an Agilent 1290 Series instrument using a $100 \mathrm{~mm} \times 3 \mathrm{~mm}$ reverse phase column (Agilent Poroshell 120 EC-C18, $2.7 \mu \mathrm{m}$ particle size) with a diode array detector. Samples $(10 \mu \mathrm{L})$ were loaded onto the column equilibrated with water and acetonitrile (98:2). Compounds were eluted by a two-step gradient increasing the acetonitrile concentration to $40 \%$ over a 6 min period, then to $100 \%$ over $4 \mathrm{~min}$, followed by an isocratic step of $2 \mathrm{~min}$, at a flow rate of $0.5 \mathrm{~mL} / \mathrm{min}$. Hormones were detected with an Agilent 6530 Quadrupole Time-of-Flight (Q-TOF) mass spectrometer in positive electrospray ionization, based on comparison with commercial standards on both mass and UV $(280 \mathrm{~nm})$ chromatograms, along with accurate mass and UV spectra.

\section{Statistical Analysis}

Heatmaps were analyzed using R "pheatmap" package (Kolde, 2012). Clustering analysis was performed using Euclidean distance method or Spearman correlation. For each condition, data were log-transformed for normal distribution and variance homogeneity, and a two-way ANOVA and Tukey's HSD tests were performed to detect soil or variety impact on fluorescent Pseudomonas population size. Pseudomonas proportions were compared with a $\chi^{2}$ test, or Fisher's exact test when the expected values in any of the cells of a contingency table were below 5 . Numbers of Pseudomonas isolates were compared by ANOVA and Fisher's LSD tests. All analyses were performed at $P<0.05$, using R software (Venables and Smith, 2011). Results in text and figures are presented as means \pm standard error.

\section{RESULTS}

\section{Enumeration of Culturable Fluorescent Pseudomonas in Bulk Soil and Maize Rhizospheres}

In all conditions, culturable fluorescent Pseudomonas populations were significantly more abundant in rhizosphere soil than in the corresponding bulk soil (Supplementary Figure S1). The mean number of culturable fluorescent Pseudomonas did not differ according to the maize cultivar $(7.09 \pm 0.26 \mathrm{log}$ cells/g for PR37Y15 and $6.99 \pm 0.22 \mathrm{log}$ cells/g for DK315; $P=0.064)$, but the interaction between soils and cultivars was significant $(P=0.032)$. Indeed, in Ysa5 soil, pseudomonads were more abundant in PR37Y15 than in DK315 maize rhizosphere, whereas no significant differences were observed between cultivars in the three other soils. In addition, the number of culturable fluorescent pseudomonads in the rhizosphere differed according to the soil for cultivar PR37Y15 but not for DK315 (Supplementary Figure S1).

\section{Distribution of Plant-Beneficial Properties in Bulk Soils and Rhizospheres}

Among the 698 isolated Pseudomonas, 209 isolates were isolated from PR37Y15 maize rhizospheres, 255 from DK315 rhizospheres and 234 from bulk soils (Table 1). A total of 18 plant-beneficial properties were targeted among the 698 Pseudomonas isolates obtained. Whereas the nitrogen fixation gene nifH, as well as the ability to synthesize indole-butyric acid, trans-zeatin, trans-zeatin riboside, isopentenyl adenosine or 6-benzylaminopurine, were not found in any isolates from the library, the 12 other plant-beneficial properties studied were 


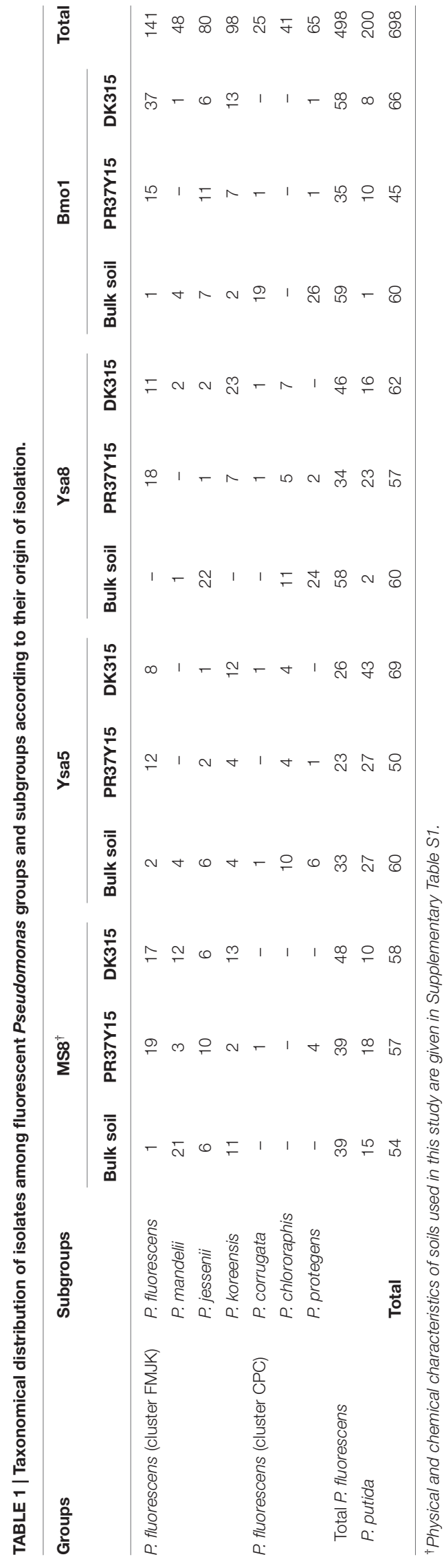

found in $2 \%$ (extracellular chitinase activity) to $96 \%$ (production of IAA) of the 698 pseudomonads. When considering together the 12 displayed plant-beneficial properties, a total of 175 different combinations (i.e., functional profiles) were found among the 698 isolates. When data from all soils were pooled together, no significant differences were observed when comparing the proportion of isolates displaying a given plantbeneficial property, in bulk soil and PR37Y15 and DK315 maize rhizospheres, regardless of the property tested ( $\chi^{2}$ tests, $P>0.05$ for each plant-beneficial property; Figure 1). When soil treatments were analyzed separately (Figure 2), the distribution of these properties in pseudomonads differed according to soil type and maize cultivar, especially for properties involved in the biosynthesis of antimicrobial compounds (i.e., DAPG, pyrrolnitrin, pyoluteorin) found in lower proportion in PR37Y15 and DK315 maize rhizospheres than bulk soil for Bmol ( $P$-value of $\chi^{2}$ tests from $10^{-10}$ to 0.04 ). For the same soil, however, the proportion of Pseudomonas harboring acdS gene was higher in both maize rhizospheres than bulk soil $(P<0.01$; Figure 2$)$. Conversely, in MS8 soil, proportions of Pseudomonas harboring genes involved in the biosynthesis of antimicrobial compounds (i.e., DAPG, pyrrolnitrin, pyoluteorin and phenazine) were higher in both maize rhizospheres than bulk soil ( $P$-value of $\chi^{2}$ tests from $10^{-12}$ to 0.05 ) whereas acdS was higher in bulk soil than both maize rhizospheres $(P<0.05)$. In the other two soils, no significant differences were detected for the distribution of each property.

When considering the numbers (rather than relative proportions) of fluorescent Pseudomonas - estimated by multiplying the Pseudomonas proportions with the raw population levels from each bulk and rhizosphere soil, and thereafter pooling together data from all soils - a higher number of pseudomonads harboring each property studied was found in the rhizosphere of one (i.e., PR37Y15 for phlD, $p r n D, p l t C$ ) or both maize cultivars (i.e., $p h z C D$, acdS, nirS, extracellular protease activity, $\mathrm{HCN}$ and IAA production, phosphate solubilization) than in the bulk soil, by approximately two orders of magnitude (Supplementary Figure S2). Numbers of kinetin producers and of pseudomonads with chitinase activity were below $2 \log$ cells/g in all three treatments.

\section{Distribution of Pseudomonas Isolates in Bulk Soils and Rhizospheres According to the Number and Assortment of Plant-Beneficial Properties They Harbor}

Pseudomonas isolates possessed from 0 (11 isolates) to a maximum of 9 ( 1 isolate) co-occurring plant-beneficial properties (i.e., functions harbored by a same isolate) among the 18 plantbeneficial properties targeted, with a mean of 3.6 properties per isolate. To assess whether maize preferentially selects fluorescent Pseudomonas harboring a high number of co-occurring plantbeneficial properties, the number of co-occurring plant-beneficial properties per isolate was analyzed according to their origin of isolation (rhizospheres or bulk soils). When data from all soils were pooled together, most rhizosphere isolates (433 of 464 rhizosphere isolates, i.e., 93\%) displayed one to five co-occurring 


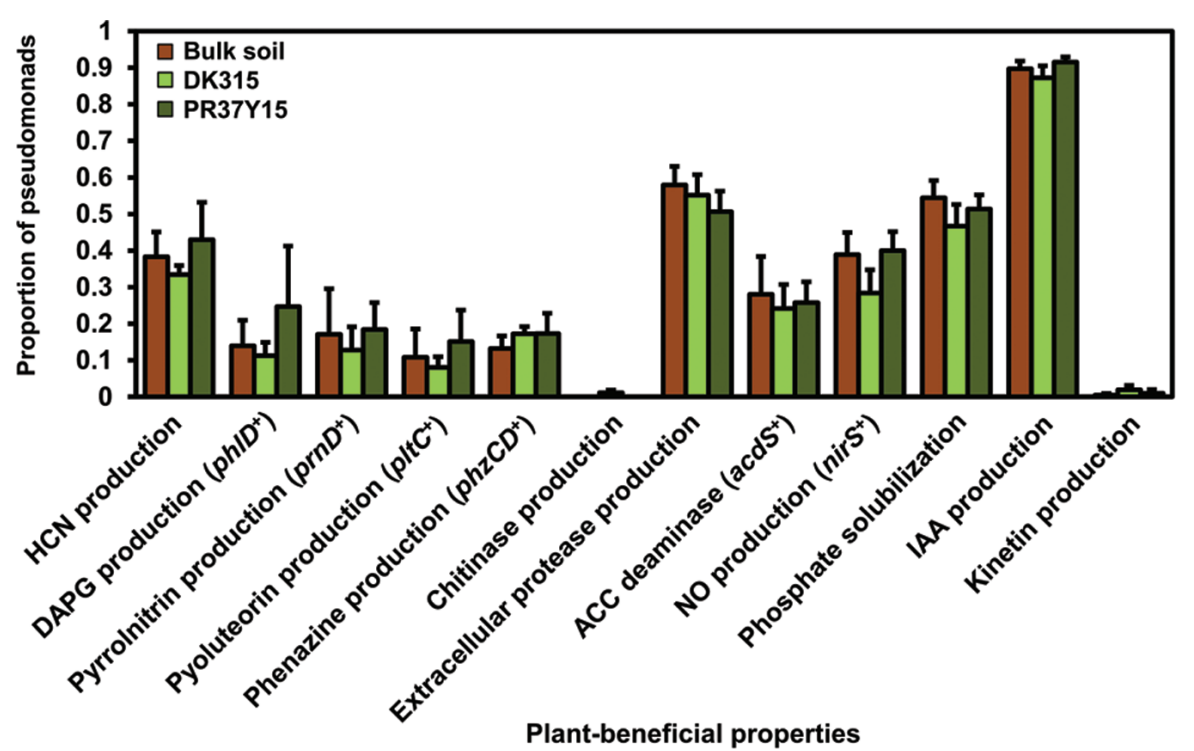

FIGURE 1 | Proportion of pseudomonads according to the type of plant-beneficial properties harbored, in bulk soil and in DK315 and PR37Y15 maize rhizospheres. Data from soils Bmo1, Ysa5, MS8, and Ysa8 were combined and error bars (standard errors) reflect the variability among the four soils. HCN, hydrogen cyanide; DAPG, 2,4-diacetylphloroglucinol; ACC, 1-amino-cyclopropane carboxylic acid; NO, nitric oxide.

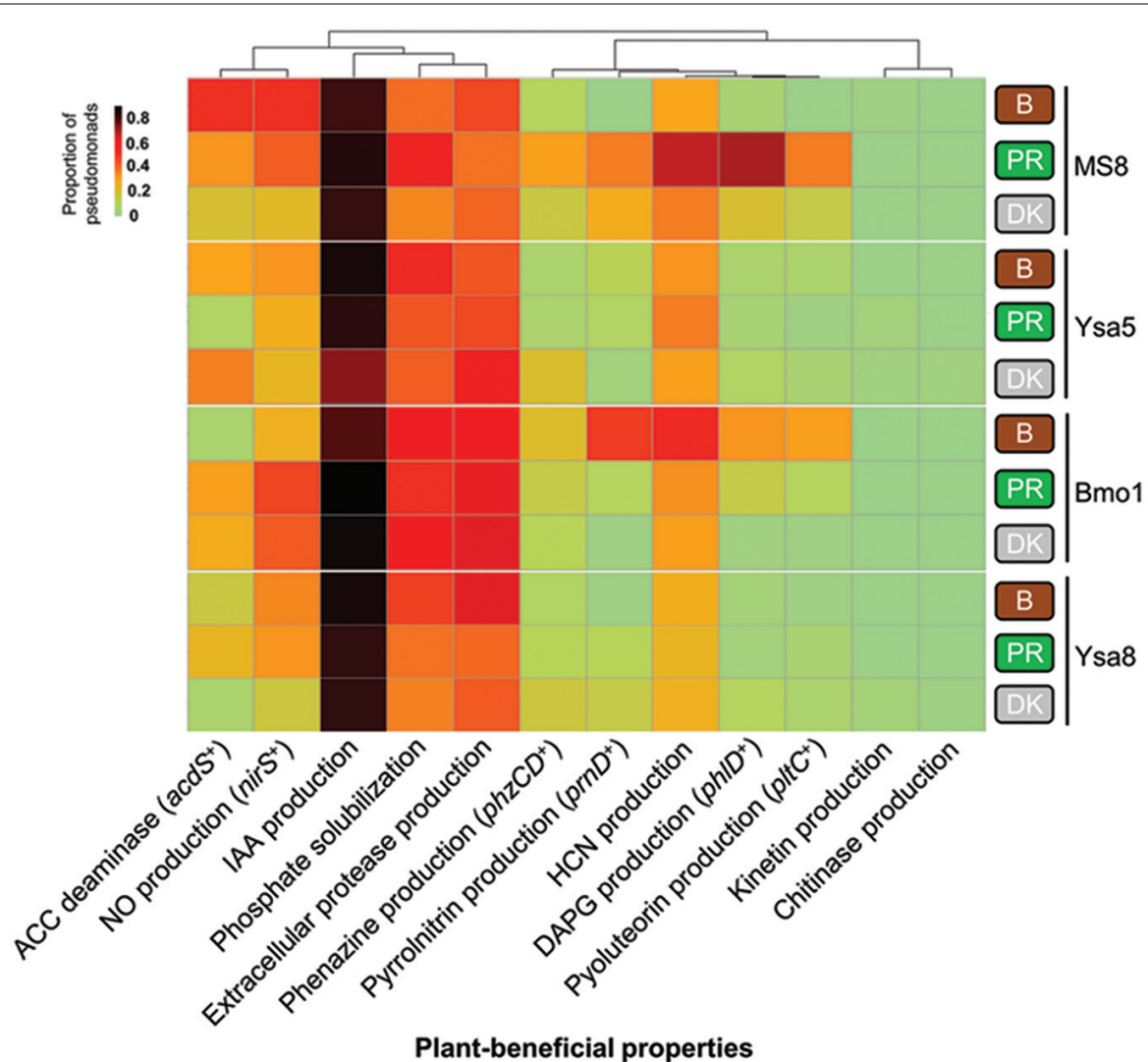

FIGURE 2 | Prevalence of plant-beneficial properties in pseudomonads in bulk soil and in DK315 and PR37Y15 maize rhizospheres at 21 days in soils Bmo1, Ysa5, MS8, and Ysa8. The heatmap represents the proportion of fluorescent pseudomonads harboring each plant-beneficial property amongst the 12 targeted and detected ones. Column clustering was performed using the correlation method. B, Bulk soil (brown rounded rectangles); PR, cultivar PR37Y15 (green rounded rectangles); DK, cultivar DK315 (gray rounded rectangles). 


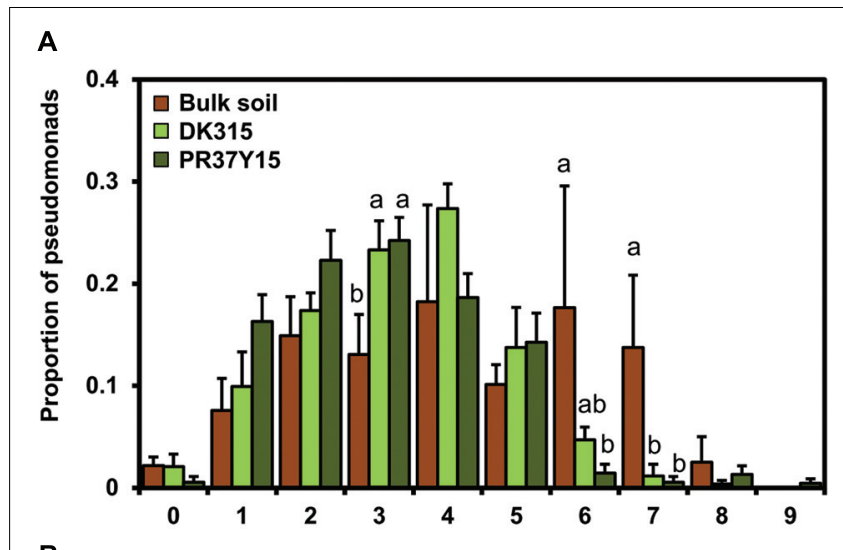

B

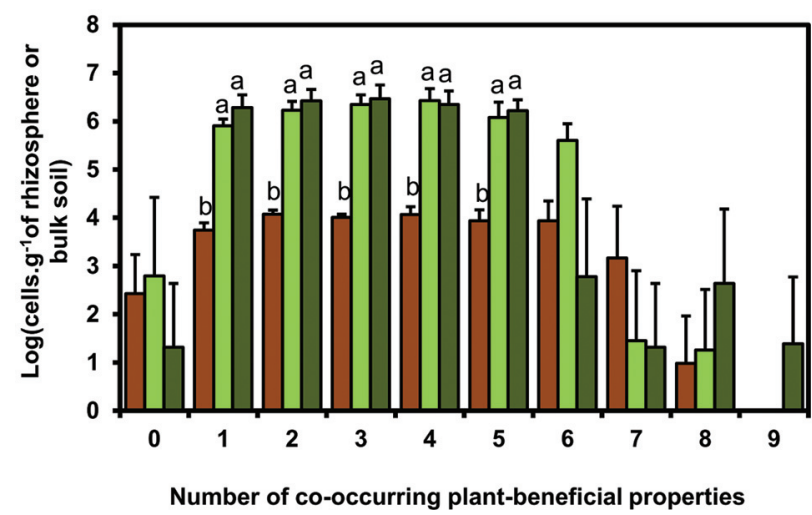

FIGURE 3 | Proportion (A) and estimated number (B) of pseudomonads according to the number of co-occurring plant-beneficial properties harbored (from 0 to 9), in bulk soil and in DK315 and PR37Y15 maize rhizospheres. Data from soils Bmo1, Ysa5, MS8, and Ysa8 were combined and error bars (standard errors) reflect the variability among the four soils. The number of Pseudomonas was estimated by multiplying the Pseudomonas proportions with the population levels quantified in each bulk and rhizosphere soil. Statistical differences between conditions (bulk soil/PR37Y15/DK315) are indicated with letter a-b (ANOVA and Fisher's LSD tests. $P<0.05$ ).

plant-beneficial properties per isolate, whereas 81 of 234 bulk soil isolates (i.e., 35\%) displayed six to nine of them (Figure 3A). When considering each soil separately, the same proportion distribution of Pseudomonas sharing 0 to 9 co-occurring plantbeneficial properties per isolate was found in the maize PR37Y15 and DK315 rhizospheres (from $P=0.32$ for Ysa8 soil to $P=0.56$ for Bmol soil; Supplementary Figure S3). In addition, the distribution was similar for bulk soil and rhizosphere in MS8 and Ysa5 soils (Supplementary Figures S3A,B) whereas it differed in soils Ysa8 and Bmol (Supplementary Figures S3C,D). When population levels were estimated for fluorescent Pseudomonas harboring various numbers of co-occurring plantbeneficial properties and data from all soils were pooled together, it appeared that the numbers of culturable fluorescent Pseudomonas harboring up to five plant-beneficial properties reached about 6 log cells/g in the maize rhizosphere of both PR37Y15 and DK315, but only $4 \mathrm{log}$ cells/g in bulk soil $(P<0.001$; Figure 3B). In contrast, pseudomonads with six to nine plant-beneficial properties were found in the maize rhizospheres in similar substantial numbers, with $2.25 \pm 0.47$ $\log$ cells/g for PR37Y15 and $2.77 \pm 1.42 \mathrm{log}$ cells/g for DK315 compared with bulk soil (2.70 $\pm 0.88 \mathrm{log}$ cells/g; Figure 3$)$.

Among the 698 isolates, the ratio of the number of functional profiles (i.e., different associations of plant-beneficial properties in isolates) to the number of isolates was significantly higher $(P=0.030)$ in PR37Y15 $(0.56 \pm 0.02)$ compared to DK315 (0.45 \pm 0.03$)$ maize rhizosphere and bulk soil $(0.45 \pm 0.05)$. However, correspondence analysis indicated that bulk soil and rhizospheres overlapped completely when assessing Pseudomonas isolate profiles (Supplementary Figure S4). Results thus point to a lack of selection of pseudomonads with specific assortments of plant-beneficial properties in the rhizosphere.

Some plant-beneficial properties preferentially co-occurred in Pseudomonas isolates. Genes for synthesis of organic antimicrobial compounds (i.e., DAPG, pyrrolnitrin, pyoluteorin and phenazines) grouped together following hierarchical clustering analysis (Figure 2) and significantly correlated with one another (Supplementary Figure S5). Likewise, properties involved in modulation of plant hormonal balance (i.e., ACC deaminase activity gene acdS and NO production gene nirS, which correlated positively; $r=0.70, P<0.011$, Supplementary Figure S5), phosphate solubilization, extracellular protease activity and HCN production grouped together (Figure 2).

\section{Taxonomic Characterization of Fluorescent Pseudomonas Isolates}

In order to characterize taxonomically the Pseudomonas isolates, rpoD amplification and sequencing were performed using specific primers for the $P$. fluorescens group, which was successful for 498 isolates (60\% of PR37Y15 isolates, $82 \%$ for DK315 isolates and $81 \%$ of bulk soil isolates; i.e., $70 \%$ overall Pseudomonas isolates). The 16S rRNA rrs gene sequencing on the 200 remaining isolates affiliated all of them to the $P$. putida group. rpoD phylogeny (Supplementary Figure S6) enabled affiliation of the rpoD-sequenced isolates to 7 of the 9 subgroups of the $P$. fluorescens group proposed by Garrido-Sanz et al. (2016), i.e., the subgroups $P$. corrugata (3.6\% of isolates), $P$. chlororaphis (5.9\%), P. protegens (9.3\%), P. fluorescens (20.2\%), P. mandelii (6.9\%), P. jessenii (11.5\%), or P. koreensis (14.0\%; Figure 4A; Supplementary Figure S6; Table 1). According to the phylogenies of Gomila et al. (2015) and Garrido-Sanz et al. (2016), two clusters, hereafter termed clusters FMJK (for the P. fluorescens, P. mandelii, P. jessenii, P. koreensis subgroups) and CPC (for the $P$. chlororaphis, $P$. protegens, $P$. corrugata subgroups), were defined in this study.

\section{Distribution of Plant-Beneficial Properties According to Pseudomonas Subgroups}

The distribution of plant-beneficial properties was assessed according to their affiliation to the $7 P$. fluorescens subgroups recovered in this study (Figure 4; Table 2). The $P$. chlororaphis subgroup shared the highest functional diversity with 12 distinct plant-beneficial properties recovered among isolates from this subgroup (regardless of their co-occurrence) whereas strains affiliated to $P$. koreensis subgroup shared the lowest functional 
A

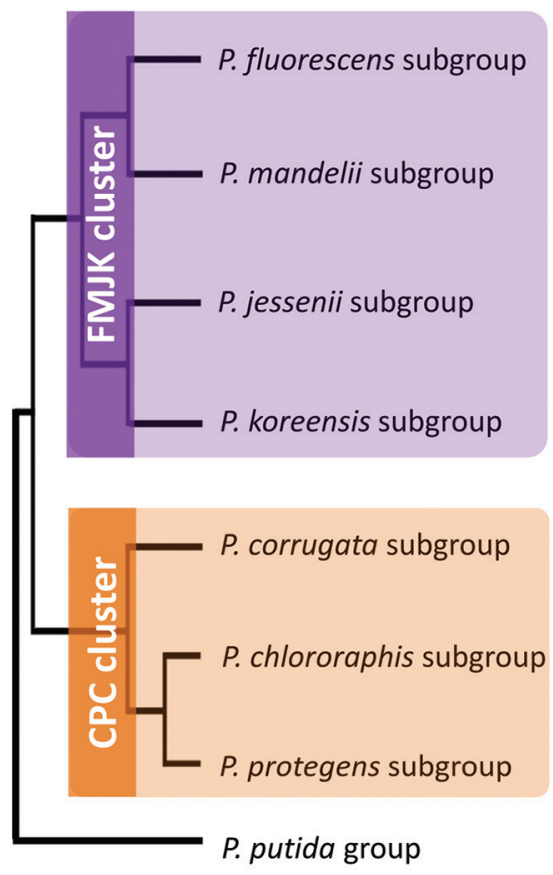

B
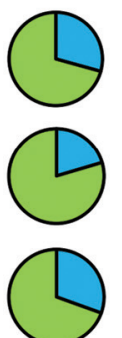

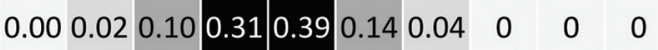

Number of co-occurring plant-beneficial properties

\begin{tabular}{ll|l|l|l|l|l|l|l|l|}
0 & 1 & 2 & 3 & 4 & 5 & 6 & 7 & 8 & 9
\end{tabular}

$\begin{array}{lllllllllll}0 & 0.04 & 0.13 & 0.26 & 0.31 & 0.19 & 0.04 & 0.03 & 0 & 0\end{array}$

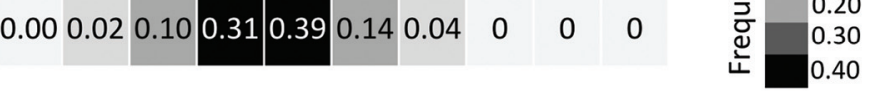

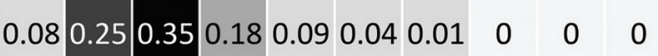

\begin{tabular}{lll|l|l|l|lllll}
0 & 0.07 & 0.12 & 0.25 & 0.35 & 0.21 & 0 & 0 & 0 & 0
\end{tabular}

$\begin{array}{lllllllllllll}0 & 0 & 0 & 0.08 & 0.08 & 0.12 & 0.32 & 0.32 & 0.08 & 0\end{array}$

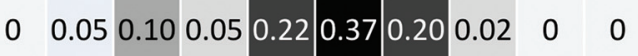

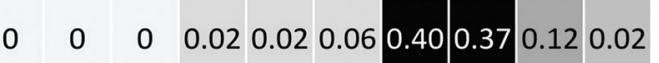

\begin{tabular}{ll|l|l|l|l|l|l|l|l|l|l|l|l|l}
0.03 & 0.24 & 0.30 & 0.23 & 0.15 & 0.04 & 0.02 & 0.01 & 0 & 0
\end{tabular}

Plant-hormonal and nutrition properties Biocontrol properties

FIGURE 4 | Distribution of plant-beneficial properties in Pseudomonas isolates according to (A) their taxonomic affiliation and (B) number of co-occurring plant-beneficial properties per isolate among the $\mathbf{1 8}$ plant-beneficial properties analyzed. The topology of the cladogram has been drawn according to the phylogenetic classification of Gomila et al. (2015). Both clusters are indicated. Biocontrol properties include production of antimicrobial compounds such as DAPG, pyrrolnitrin, pyoluteorin, phenazine, and $\mathrm{HCN}$, and production of extracellular protease and chitinase. Plant hormonal and nutrition properties regroup ACC deaminase, production of NO, kinetin and IAA and phosphate solubilization.

diversity (i.e., 8 distinct plant-beneficial properties; Table 2). The number of plant-beneficial properties found per isolate (i.e., cooccurring properties) was significantly lower $(P<0.001)$ for the FMJK cluster $(3.36 \pm 0.07$ properties per isolate) than the CPC cluster ( $5.76 \pm 0.13$ properties; Figure 4B).

The ecological functions conferred by plant-beneficial properties harbored by isolates also differed according to the taxonomic affiliation of Pseudomonas isolates. When regrouping plant-beneficial properties according to their type of action, differences between Pseudomonas subgroups were observed regarding the proportion of (i) biocontrol properties (i.e., genes for antimicrobial compounds DAPG, pyrrolnitrin, pyoluteorin and phenazine, and production of extracellular protease, chitinase, and $\mathrm{HCN}$ ) and (ii) properties related to plant hormonal balance modulation and plant nutrition (i.e., ACC deaminase and NO genes, production of kinetin and IAA, and phosphate solubilization; Figure 4A). Overall, higher proportions of biocontrol properties were found in isolates belonging to the CPC cluster (68\% for P. chlororaphis, $67 \%$ for $P$. protegens and $50 \%$ for $P$. corrugata subgroups) than among most members of the FMJK cluster $(29 \%$ for P. fluorescens, $20 \%$ for P. mandelii, 30\% for P. jessenii and $56 \%$ for $P$. koreensis subgroups; Figure 4A). Conversely, phytostimulatory properties (i.e., plant hormone modulation and nutrition properties) were found, for the most part, in higher proportion in FMJK isolates (71\% for P. fluorescens, 80\% for P. mandelii, $70 \%$ for $P$. jessenii and $44 \%$ for $P$. koreensis subgroups) than CPC isolates $(32 \%$ for $P$. chlororaphis, $33 \%$ for $P$. protegens and $50 \%$ for $P$. corrugata subgroups; Figure 4A).

The proportions of all individual biocontrol properties in the pseudomonads were also higher $(P<0.001$ each) in cluster CPC than FMJK (Table 2). Contrariwise, all properties related to plant hormonal balance modulation and plant nutrition were found in similar proportions in CPC and FMJK clusters.

Isolates belonging to the $P$. putida group displayed more plant-beneficial properties related to plant hormonal balance modulation and plant nutrition than to biocontrol (Figure 4A). Moreover, these isolates harbored a low number of co-occurring plant-beneficial properties, i.e., $2.5 \pm 0.1$ (Figure 4B). 


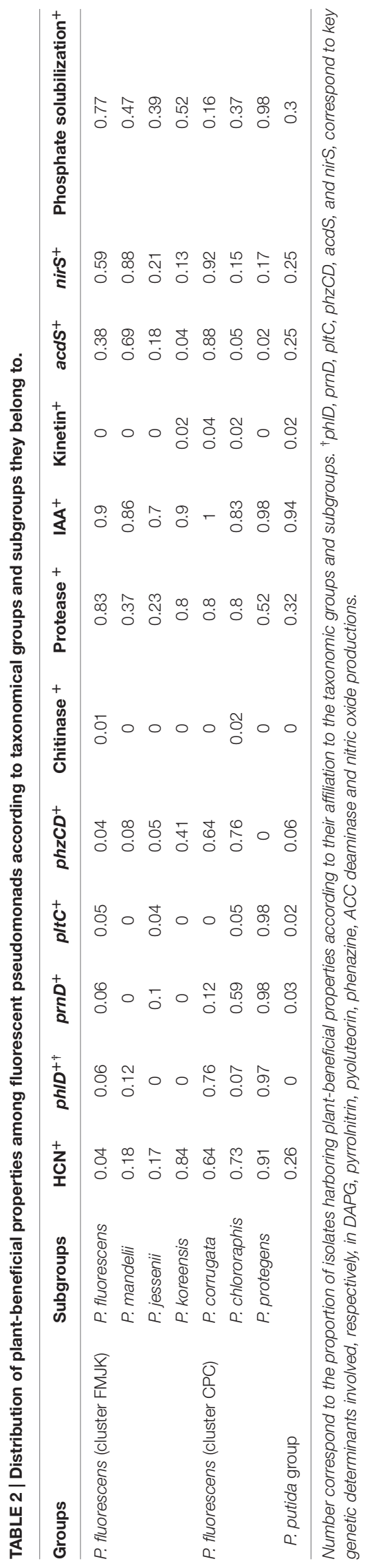

\section{Maize Selection and Distribution of Pseudomonas CPC and FMJK Clusters and of $P$. putida}

The FMJK and CPC clusters were present in the same relative proportion (40\%) in bulk soil, but in the rhizosphere, FMJK isolates were retrieved in a significantly higher proportion than CPC isolates (up to $60 \%$ for FMJK versus below $10 \%$ for CPC; Figure 5). The P. putida group was found in the same proportion in bulk soil and in the rhizosphere. The proportion of this group was significantly more important than that of the CPC cluster in PR37Y15 maize rhizosphere (Figure 5). The same trends were observed when considering the estimated number of Pseudomonas from FMJK and CPC clusters, in bulk soils or rhizospheres (Supplementary Figure S7).

When considering the amounts of co-occurring plantbeneficial properties per isolate, FMJK isolates with one to five plant-beneficial properties were more abundant than FMJK isolates with six to nine plant-beneficial properties in all soils $(P<0.001$; Figure 6A). This was also the case when considering estimated Pseudomonas population levels (Supplementary Figure S7B).

In parallel, the proportions of isolates belonging to CPC cluster with six to nine plant-beneficial properties were smaller in the rhizospheres of both cultivars $(P=0.002)$ than in bulk soil, whereas those with one to five plant-beneficial properties were found in similar proportions in bulk soils and maize rhizospheres $(P=0.28$; Figure 6B). When considering estimated Pseudomonas population levels, the numbers of CPC isolates with one to five or six to nine plant-beneficial properties were similar between bulk soil and maize rhizospheres, except in the PR37Y15 maize rhizosphere where a higher number of CPC isolates with one to five plant-beneficial properties was found than in the other conditions (Supplementary Figure S7C).

In conclusion, the selection of Pseudomonas strains in the maize rhizosphere depends more on the number of plantbeneficial properties they harbor than the Pseudomonas cluster they belong to.

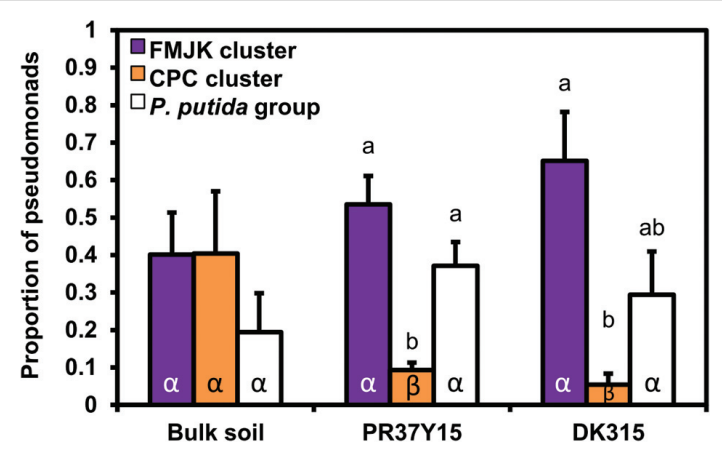

FIGURE 5 | Comparison of the proportion of pseudomonads belonging to FMJK and CPC clusters and to $P$. putida group in bulk soil and in the PR37Y15 and DK315 maize rhizospheres. Error bars correspond to standard errors. Statistical differences between subgroups are indicated with letter $a-b$ and statistical differences between conditions (bulk soil/PR37Y15/ DK315) are indicated with letter $\alpha-\beta$ (ANOVA and Fisher's LSD tests. $P<0.05$ ). 
A

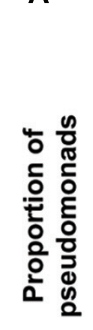

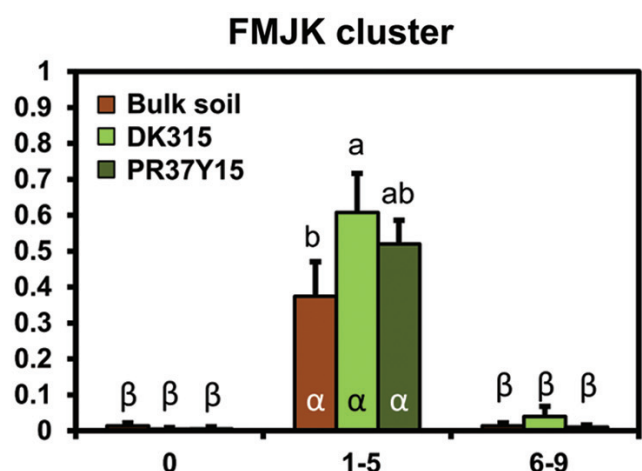

$1-5$
B

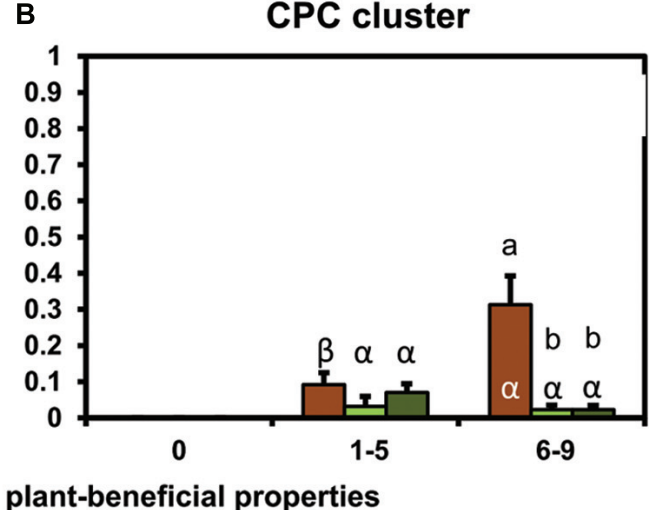

FIGURE 6 | Comparison of the proportion of pseudomonads belonging to FMJK (A) and CPC (B) clusters in bulk soil and in the PR37Y15 and DK315 maize rhizospheres according to the number of co-occurring plant-beneficial properties harbored. Error bars correspond to standard errors. Statistical differences between plant-beneficial property classes according to conditions (bulk soil/PR37Y15/DK315) are indicated with letter $\alpha-\beta$ (ANOVA and Fisher's LSD tests. $P<0.05)$. Statistical differences between conditions within plant-beneficial property class are indicated with letter a-b.

\section{DISCUSSION}

The fluorescent Pseudomonas are key models to assess beneficial plant-bacteria interactions, because they display a wide range of plant-beneficial properties and play an important role in the rhizosphere, including in disease-suppressive soils (Weller and Cook, 1983; Lemanceau and Alabouvette, 1991; O'Sullivan and O'Gara, 1992; Bakker et al., 2007; Barret et al., 2009; Almario et al., 2014b). A given Pseudomonas PGPR strain generally displays many different modes of action on the plant, which is thought to be important to maximize plant benefits. However, contrarily to expectations, we found that Pseudomonas rhizobacteria with high numbers $(>5)$ of plantbeneficial properties were not prevalent in the maize rhizosphere in our experimental conditions, as they were outcompeted by counterparts with lower numbers (1-5) of these properties. Therefore, even though Pseudomonas inoculants with high numbers of plant-beneficial properties are being sought in PGPR screening programs (Ahmad et al., 2008), their high effectiveness in short-term greenhouse trials may be counterbalanced by insufficient rhizosphere survival under field conditions, an issue long identified (Weller, 1988).

The current finding is hard to track back to literature data, as direct comparisons of Pseudomonas strains with 1-5 vs. 6-9 plant-beneficial properties are not available. The high-propertynumber CPC-cluster strain $P$. protegens CHA0 survived poorly in the rhizosphere of well-established maize and wheat (Troxler et al., 1997) and was seldom evidenced by phlD PCR-DGGE even in its habitat of origin, i.e., roots of tobacco grown in Morens suppressive soils (Frapolli et al., 2010). In contrast, pseudomonads belonging to the FMJK cluster that overall possess fewer plant-beneficial properties were prominent in, for instance, the strawberry rhizosphere based on rrs PCR-DGGE (Costa et al., 2006) and gacA PCR-DGGE (Costa et al., 2007), whereas pseudomonads related to $P$. protegens $\mathrm{CHA} 0$ were not found.

Eighteen contrasted plant-beneficial properties were screened in the Pseudomonas collection and 12 were evidenced. We recognize that results of the present study depended on the number of tested properties. Other properties like the biosynthesis of flagella, exopolysaccharides, lipopolysaccharides, or siderophores are pivotal for the colonization of host plants and adaptation to the rhizosphere (Höfte et al., 1992; Duijff et al., 1997; de Weert et al., 2002; Barahona et al., 2011). These properties are widely distributed in Pseudomonas and may not be sufficiently discriminant to use them for characterizing Pseudomonas isolate library (Luján et al., 2015).

In the maize rhizosphere, auxin production is widespread in fluorescent Pseudomonas (Picard et al., 2004; Picard and Bosco, 2005), as was confirmed here, but (i) it is often deduced from the Salkowski colorimetric assay, which responds also to other indolic compounds (Glickmann and Dessaux, 1995; Szkop and Bielawski, 2012), and (ii) different auxins may play different roles in plant (Simon and Petrášek, 2011). Therefore, a UHPLC approach coupled with a diode array detector was implemented to detect different types of auxins (and cytokinins), which showed that only indole-3-acetic acid (and the cytokinin kinetin) was produced in pure culture by pseudomonads. We cannot exclude that the other types of tracked auxins and cytokinins could be produced by Pseudomonas isolates in other conditions, such when interacting with the host plant. The gene nifH, which occurs in certain Pseudomonas strains (Mirza et al., 2006), was not evidenced here.

The distribution of plant-beneficial properties in pseudomonads was not random, as co-occurrence patterns were found. This concerned acdS (ACC deaminase) and nirS (nitrite reductase), both involved in the modulation of plant hormonal balance and plant defenses (Glick, 2005; Vacheron et al., 2015), which suggests possible fine tuning of plant hormonal conditions by rhizosphere Pseudomonas populations. It was also the case for $a c d S$ and indole-3-acetic acid, in line with the observation that auxins stimulate ACC synthase activity in roots (Glick et al., 1998). Finally, the co-occurrence of genes for production of organic antimicrobial compounds, which is well 
documented in model strains (Ramette et al., 2003; Haas and Défago, 2005; Raaijmakers et al., 2006; Mazurier et al., 2009), raises the possibility of additive or even synergistic effects in phytoprotection (Clifford et al., 2015).

A broader study analyzed the distribution of plant-beneficial properties among a total of 304 genomes of Proteobacteria with different ecologies (Bruto et al., 2014). Among the 25 PGPR sequenced genomes, the co-occurrence between $p h l$ and hon genes was found. In contrast, no relation was described between the ACC deaminase gene and the nitrite reductase gene involved in NO production (Bruto et al., 2014), a co-occurence that we observed in the present study. This can be explained by the fact that the present study targeted a lower taxonomic level (i.e., Pseudomonas fluorescens group and Pseudomonas putida group). In addition, the identification of specific co-occurrence between plant-beneficial properties may be influenced by phylogenetic signal phenomenon, i.e., the tendency of related species to be more similar to each other than two species taken randomly from a same phylogenetic tree (Münkemüller et al., 2012; Bruto et al., 2014).

Differences in plant-beneficial property distributions were found between (i) the four soils (Figure 2), (ii) bulk soil and rhizosphere, and (iii) the two maize cultivars, as could be expected in relation to documented rhizosphere effects (Marschner et al., 2001; Berg and Smalla, 2009; İnceoğlu et al., 2012). In the current study, the plant-beneficial profiles harbored by pseudomonads in DK315 rhizosphere were less diversified than those found in PR37Y15 maize rhizosphere (Supplementary Figure S4). Moreover, the pseudomonads proportions of $p h l D^{+}$, prnD ${ }^{+}, p l t C^{+}$, and $p h z C D^{+}$were higher in PR37Y15 maize rhizosphere than in DK315 maize rhizosphere in the two soils Bmo1 and Ysa8. Similarly, a plant selection effect was found toward $p h l D^{+}$pseudomonads isolates between three different maize genotypes, showing a significant higher abundance of phlD ${ }^{+}$pseudomonads in the rhizosphere of a maize hybrid than in its parent lines (Picard and Bosco, 2005). Indeed, maize genotypes may select distinct plant-beneficial functional groups. In turn, these plant genotypes may respond differentially to PGPR (Walker et al., 2011), which can express plant-beneficial genes at different levels according to maize genotype (Rice et al., 2011; Vacheron et al., 2016).

Among the seven subgroups (Mulet et al., 2010) evidenced here from the $P$. fluorescens group, the four FMJK subgroups included pseudomonads with a lower number of cooccurring plant-beneficial properties compared with the three CPC subgroups, in which biocontrol properties were more prevalent. It is interesting to note that the lower rhizosphere competitiveness of CPC pseudomonads tends to affect particularly strains with 6-9 plant-beneficial properties in comparison with CPC pseudomonads with $1-5$ of these properties (Figure 6B). Results suggest that there is a trade-off between rhizosphere prevalence and the ability to maintain a large number of plant-beneficial properties in the rhizosphere environment, where competition for rhizodeposits and other root exudates is high (Bais et al., 2006). This may have functional implications, as the two CPC and FMJK Pseudomonas subgroups tend to implement different arrays of plant-beneficial effects (phytostimulation vs. biocontrol) in the rhizosphere, and it is tempting to speculate that their joint contributions may be useful to optimize symbiotic benefits for root system functioning. Even if maize selected Pseudomonas rhizobacteria harboring few plant-beneficial properties $(<5)$, all plant-beneficial properties were represented in the rhizosphere Pseudomonas populations. Maize may maximize the taxonomic diversity and functional redundancy of Pseudomonas populations, thereby allowing a better allocation of ecological tasks among the rhizomicrobiota. This is in line with co-inoculation experiments of different bacterial and/or fungal strains, which offer a functional complementarity between the plant-beneficial actions they display and enhanced positive effects on the host plant (Srivastava et al., 2010; Combes-Meynet et al., 2011; Couillerot et al., 2012). Indeed, the inoculation of consortia may also favor other symbioses in the rhizosphere, as the inoculation of two pseudomonads increased the number of rhizobial root nodules and improved symbiotic performance (Egamberdieva et al., 2010).

\section{CONCLUSION}

This report suggests that plants shape the composition of Pseudomonas populations by preferentially selecting pseudomonads harboring one to five plant-beneficial properties. This is the first study that characterizes fluorescent Pseudomonas populations in the rhizosphere according to the type and number of plant-beneficial properties they harbor and their taxonomic status.

\section{AUTHOR CONTRIBUTIONS}

JV, DM, and CP-C conceived and designed the experiments. JV performed the experiment. MG-M contributed to plant hormone analysis. JV, YM-L, DM, AD, and CP-C analyzed the data and JV, YM-L, DM, and CP-C wrote the manuscript; all authors contributed to the discussion and approved the final manuscript.

\section{FUNDING}

JV was supported by a Ph.D. grant from Academic Research Cluster 3 of Rhône-Alpes Region. This study was supported by the ANR project SymbioMaize (ANR-12-JSV7-0014-01).

\section{ACKNOWLEDGMENTS}

We are grateful to the iBio platform (UMR CNRS 5557 Ecologie Microbienne) for helpful discussion. This work made use of Serre technical platform of FR3728 BioEnviS at Université Lyon 1.

\section{SUPPLEMENTARY MATERIAL}

The Supplementary Material for this article can be found online at: http://journal.frontiersin.org/article/10.3389/fpls.2016.01212 


\section{REFERENCES}

Ahmad, F., Ahmad, I., and Khan, M. S. (2008). Screening of free-living rhizospheric bacteria for their multiple plant growth promoting activities. Microbiol. Res. 163, 173-181. doi: 10.1016/j.micres.2006.04.001

Almario, A., Kyselková, M., Kopecký, J., Ságová-Marečková, M., Muller, D., Grundmann, G. L., et al. (2013). Assessment of the relationship between geologic origin of soil, rhizobacterial community composition and soil receptivity to tobacco black root rot in Savoie region (France). Plant Soil 371, 397-408. doi: 10.1007/s11104-013-1677-1

Almario, J., Gobbin, D., Défago, G., Moënne-Loccoz, Y., and Rezzonico, F. (2014a). Prevalence of type III secretion system in effective biocontrol pseudomonads. Res. Microbiol. 165, 300-304. doi: 10.1016/j.resmic.2014.03.008

Almario, J., Muller, D., Défago, G., and Moënne-Loccoz, Y. (2014b). Rhizosphere ecology and phytoprotection in soils naturally suppressive to Thielaviopsis black root rot of tobacco. Environ. Microbiol. 16, 1949-1960. doi: 10.1111/14622920.12459

Arese, M., Zumft, W. G., and Cutruzzolà, F. (2003). Expression of a fully functional cd1 nitrite reductase from Pseudomonas aeruginosa in Pseudomonas stutzeri. Protein Expr. Purif. 27, 42-48. doi: 10.1016/S1046-5928(02)00600-9

Bais, H. P., Weir, T. L., Perry, L. G., Gilroy, S., and Vivanco, J. M. (2006). The role of root exudates in rhizosphere interactions with plants and other organisms. Annu. Rev. Plant Biol. 57, 233-266. doi: 10.1146/annurev.arplant. 57.032905.105159

Bakker, P. A. H. M., Glandorf, D. C. M., Viebahn, M., Ouwens, T. W. M., Smit, E., Leeflang, P., et al. (2002). Effects of Pseudomonas putida modified to produce phenazine-1-carboxylic acid and 2,4-diacetylphloroglucinol on the microflora of field grown wheat. Antonie Van Leeuwenhoek 81, 617-624. doi: 10.1023/A:1020526126283

Bakker, P. A. H. M., Pieterse, C. M. J., and van Loon, L. C. (2007). Induced systemic resistance by fluorescent Pseudomonas spp. Phytopathology 97, 239-243. doi: 10.1094/PHYTO-97-2-0239

Barahona, E., Navazo, A., Martínez-Granero, F., Zea-Bonilla, T., Pérez-Jiménez, R. M., Martín, M., et al. (2011). Pseudomonas fluorescens F113 mutant with enhanced competitive colonization ability and improved biocontrol activity against fungal root pathogens. Appl. Environ. Microbiol. 77, 5412-5419. doi: 10.1128/AEM.00320-11

Barret, M., Frey-Klett, P., Boutin, M., Guillerm-Erckelboudt, A.-Y., Martin, F., Guillot, L., et al. (2009). The plant pathogenic fungus Gaeumannomyces graminis var. tritici improves bacterial growth and triggers early gene regulations in the biocontrol strain Pseudomonas fluorescens Pf29Arp. New Phytol. 181, 435-447. doi: 10.1111/j.1469-8137.2008.02675.x

Bashan, Y., and de-Bashan, L. E. (2010). Chapter two - How the plant growth-promoting bacterium Azospirillum promotes plant growth-a critical assessment. Adv. Agron. 108, 77-136.

Baudoin, E., Lerner, A., Mirza, M. S., El Zemrany, H., Prigent-Combaret, C., Jurkevich, E., et al. (2010). Effects of Azospirillum brasilense with genetically modified auxin biosynthesis gene ipdC upon the diversity of the indigenous microbiota of the wheat rhizosphere. Res. Microbiol. 161, 219-226. doi: 10.1016/j.resmic.2010.01.005

Baudouin, E., and Hancock, J. T. (2014). Nitric oxide signaling in plants. Front. Plant Sci. 4:553. doi: 10.3389/fpls.2013.00553

Berg, G., and Smalla, K. (2009). Plant species and soil type cooperatively shape the structure and function of microbial communities in the rhizosphere. FEMS Microbiol. Ecol. 68, 1-13. doi: 10.1111/j.1574-6941.2009.00654.x

Brazelton, J. N., Pfeufer, E. E., Sweat, T. A., McSpadden Gardener, B. B., and Coenen, C. (2008). 2,4-diacetylphloroglucinol alters plant root development. Mol. Plant Microbe Interact. 21, 1349-1358. doi: 10.1094/MPMI-21-10-1349

Bruto, M., Prigent-Combaret, C., Muller, D., and Moënne-Loccoz, Y. (2014). Analysis of genes contributing to plant-beneficial functions in plant growthpromoting rhizobacteria and related Proteobacteria. Sci. Rep. 4:6261. doi: 10.1038/srep06261

Clifford, J. C., Buchanan, A., Vining, O., Kidarsa, T. A., Chang, J. H., McPhail, K. L., et al. (2015). Phloroglucinol functions as an intracellular and intercellular chemical messenger influencing gene expression in Pseudomonas protegens. Environ. Microbiol. doi: 10.1111/1462-2920.13043 [Epub ahead of print].

Combes-Meynet, E., Pothier, J. F., Moënne-Loccoz, Y., and Prigent-Combaret, C. (2011). The Pseudomonas secondary metabolite 2,4-diacetylphloroglucinol is a signal inducing rhizoplane expression of Azospirillum genes involved in plant-growth promotion. Mol. Plant Microbe Interact. 24, 271-284. doi: 10.1094/MPMI-07-10-0148

Costa, R., Gomes, N. C. M., Krögerrecklenfort, E., Opelt, K., Berg, G., and Smalla, K. (2007). Pseudomonas community structure and antagonistic potential in the rhizosphere: insights gained by combining phylogenetic and functional gene-based analyses. Environ. Microbiol. 9, 2260-2273. doi: 10.1111/j.1462-2920.2007.01340.x

Costa, R., Götz, M., Mrotzek, N., Lottmann, J., Berg, G., and Smalla, K. (2006). Effects of site and plant species on rhizosphere community structure as revealed by molecular analysis of microbial guilds. FEMS Microbiol. Ecol. 56, 236-249. doi: 10.1111/j.1574-6941.2005.00026.x

Couillerot, O., Ramírez-Trujillo, A., Walker, V., von Felten, A., Jansa, J., Maurhofer, M., et al. (2012). Comparison of prominent Azospirillum strains in Azospirillum-Pseudomonas-Glomus consortia for promotion of maize growth. Appl. Microbiol. Biotechnol. 97, 4639-4649. doi: 10.1007/s00253-012-4249-z

de Souza, J. T., Arnould, C., Deulvot, C., Lemanceau, P., Gianinazzi-Pearson, V., and Raaijmakers, J. M. (2003). Effect of 2,4-diacetylphloroglucinol on Pythium: cellular responses and variation in sensitivity among propagules and species. Phytopathology 93, 966-975. doi: 10.1094/PHYTO.2003.93.8.966

de Souza, J. T., and Raaijmakers, J. M. (2003). Polymorphisms within the prnD and pltC genes from pyrrolnitrin and pyoluteorin-producing Pseudomonas and Burkholderia spp. FEMS Microbiol. Ecol. 43, 21-34. doi: 10.1111/j.15746941.2003.tb01042.x

de Weert, S., Vermeiren, H., Mulders, I. H. M., Kuiper, I., Hendrickx, N., Bloemberg, G. V., et al. (2002). Flagella-driven chemotaxis towards exudate components is an important trait for tomato root colonization by Pseudomonas fluorescens. Mol. Plant Microbe Interact. 15, 1173-1180. doi: 10.1094/MPMI.2002.15.11.1173

Duijff, B. J., Gianinazzi-Pearson, V., and Lemanceau, P. (1997). Involvement of the outer membrane lipopolysaccharides in the endophytic colonization of tomato roots by biocontrol Pseudomonas fluorescens strain WCS417r. New Phytol. 135, 325-334. doi: 10.1046/j.1469-8137.1997.00646.x

Dunne, C., Moënne-Loccoz, Y., McCarthy, J., Higgins, P., Powell, J., Dowling, D. N., et al. (1998). Combining proteolytic and phloroglucinol-producing bacteria for improved biocontrol of Pythium-mediated damping-off of sugar beet. Plant Pathol. 47, 299-307. doi: 10.1046/j.1365-3059.1998.00233.x

Edgar, R. C. (2004). MUSCLE: multiple sequence alignment with high accuracy and high throughput. Nucleic Acids Res. 32, 1792-1797. doi: 10.1093/nar/gkh340

Edwards, U., Rogall, T., Blöcker, H., Emde, M., and Böttger, E. C. (1989). Isolation and direct complete nucleotide determination of entire genes. Characterization of a gene coding for 16 S ribosomal RNA. Nucleic Acids Res. 17, 7843-7853. doi: $10.1093 / \mathrm{nar} / 17.19 .7843$

Egamberdieva, D., Berg, G., Lindström, K., and Räsänen, L. A. (2010). Coinoculation of Pseudomonas spp. with Rhizobium improves growth and symbiotic performance of fodder Galega (Galega orientalis Lam.). Eur. J. Soil Biol. 46, 269-272. doi: 10.1016/j.ejsobi.2010.01.005

Frapolli, M., Défago, G., and Moënne-Loccoz, Y. (2007). Multilocus sequence analysis of biocontrol fluorescent Pseudomonas spp. producing the antifungal compound 2,4-diacetylphloroglucinol. Environ. Microbiol. 9, 1939-1955. doi: 10.1111/j.1462-2920.2007.01310.x

Frapolli, M., Défago, G., and Moënne-Loccoz, Y. (2010). Denaturing gradient gel electrophoretic analysis of dominant 2,4-diacetylphloroglucinol biosynthetic phlD alleles in fluorescent Pseudomonas from soils suppressive or conducive to black root rot of tobacco. Soil Biol. Biochem. 42, 649-656. doi: 10.1016/j.soilbio.2010.01.005

Frapolli, M., Moënne-Loccoz, Y., Meyer, J., and Défago, G. (2008). A new DGGE protocol targeting 2,4-diacetylphloroglucinol biosynthetic gene phlD from phylogenetically contrasted biocontrol pseudomonads for assessment of disease-suppressive soils. FEMS Microbiol. Ecol. 64, 468-481. doi: 10.1111/j.1574-6941.2008.00471.x

Frapolli, M., Pothier, J. F., Défago, G., and Moënne-Loccoz, Y. (2012). Evolutionary history of synthesis pathway genes for phloroglucinol and cyanide antimicrobials in plant-associated fluorescent pseudomonads. Mol. Phylogenet. Evol. 63, 877-890. doi: 10.1016/j.ympev.2012.02.030

Friesen, T. L., Stukenbrock, E. H., Liu, Z., Meinhardt, S., Ling, H., Faris, J. D., et al. (2006). Emergence of a new disease as a result of interspecific virulence gene transfer. Nat. Genet. 38, 953-956. doi: 10.1038/ng1839 
García de Salamone, I. E., Hynes, R. K., and Nelson, L. M. (2001). Cytokinin production by plant growth promoting rhizobacteria and selected mutants. Can. J. Microbiol. 47, 404-411. doi: 10.1139/w01-029

Garrido-Sanz, D., Meier-Kolthoff, J. P., Göker, M., Martín, M., Rivilla, R., and Redondo-Nieto, M. (2016). Genomic and genetic diversity within the Pseudomonas fluorescens complex. PLoS ONE 11:e0150183. doi: 10.1371/journal.pone.0150183

Glick, B. R. (2005). Modulation of plant ethylene levels by the bacterial enzyme ACC deaminase. FEMS Microbiol. Lett. 251, 1-7. doi: 10.1016/j.femsle. 2005.07.030

Glick, B. R., Penrose, D. M., and Li, J. (1998). A model for the lowering of plant ethylene concentrations by plant growth-promoting bacteria. J. Theor. Biol. 190, 63-68. doi: 10.1006/jtbi.1997.0532

Glickmann, E., and Dessaux, Y. (1995). A critical examination of the specificity of the Salkowski reagent for indolic compounds produced by phytopathogenic bacteria. Appl. Environ. Microbiol. 61, 793-796.

Gomila, M., Peña, A., Mulet, M., Lalucat, J., and García-Valdés, E. (2015). Phylogenomics and systematics in Pseudomonas. Evol. Genomic Microbiol. 6:214. doi: 10.3389/fmicb.2015.00214

Guindon, S., Dufayard, J.-F., Lefort, V., Anisimova, M., Hordijk, W., and Gascuel, O. (2010). New algorithms and methods to estimate maximumlikelihood phylogenies: assessing the performance of PhyML 3.0. Syst. Biol. 59, 307-321. doi: 10.1093/sysbio/syq010

Haas, D., and Défago, G. (2005). Biological control of soil-borne pathogens by fluorescent pseudomonads. Nat. Rev. Microbiol. 3, 307-319. doi: $10.1038 /$ nrmicrol129

Höfte, M., Boelens, J., and Verstraete, W. (1992). Survival and root colonization of mutants of plant growth-promoting pseudomonads affected in siderophore biosynthesis or regulation of siderophore production. J. Plant Nutr. 15, 22532262. doi: 10.1080/01904169209364472

Holguin, G., and Glick, B. R. (2003). Transformation of Azospirillum brasilense Cd with an ACC deaminase gene from Enterobacter cloacae UW4 fused to the TetR gene promoter improves its fitness and plant growth promoting ability. Microb. Ecol. 46, 122-133. doi: 10.1007/s00248-002-1036-x

İnceoğlu, Ö., Falcão Salles, J., and van Elsas, J. D. (2012). Soil and cultivar type shape the bacterial community in the potato rhizosphere. Microb. Ecol. 63, 460-470. doi: 10.1007/s00248-011-9930-8

Keel, C., Wirthner, P. H., Oberhänsli, T. H., Voisard, C., Haas, D., Défago, G., et al. (1990). Pseudomonads as antagonists of plant pathogens in the rhizosphere: role of the antibiotic 2,4-diacetylphloroglucinol in the suppression of black root rot of tobacco. Symbiosis 9, 327-341.

Kim, K.-J., Yang, Y.-J., and Kim, J.-G. (2003). Purification and characterization of chitinase from Streptomyces sp. M-20. J. Biochem. Mol. Biol. 36, 185-189. doi: 10.5483/BMBRep.2003.36.2.185

Kolde, R. (2012). Pheatmap: Pretty Heatmaps. R Package Version. 61.

Kyselková, M., Kopecký, J., Frapolli, M., Défago, G., Ságová-Marecková, M., Grundmann, G. L., et al. (2009). Comparison of rhizobacterial community composition in soil suppressive or conducive to tobacco black root rot disease. ISME J. 3, 1127-1138. doi: 10.1038/ismej.2009.61

Landa, B. B., De Werd, H. A. E., McSpadden Gardener, B. B., and Weller, D. M. (2002). Comparison of three methods for monitoring populations of different genotypes of 2,4-diacetylphloroglucinol-producing Pseudomonas fluorescens in the rhizosphere. Phytopathology 92, 129-137. doi: 10.1094/PHYTO.2002.92.2.129

Latz, E., Eisenhauer, N., Rall, B. C., Scheu, S., and Jousset, A. (2016). Unravelling linkages between plant community composition and the pathogen-suppressive potential of soils. Sci. Rep. 6:23584. doi: 10.1038/srep23584

Leij, F. A. D., Dixon-Hardy, J. E., and Lynch, J. M. (2002). Effect of 2,4diacetylphloroglucinol-producing and non-producing strains of Pseudomonas fluorescens on root development of pea seedlings in three different soil types and its effect on nodulation by Rhizobium. Biol. Fertil. Soils 35, 114-121. doi: 10.1007/s00374-002-0448-6

Lemanceau, P., and Alabouvette, C. (1991). Biological control of fusarium diseases by fluorescent Pseudomonas and non-pathogenic Fusarium. Crop Prot. 10, 279-286. doi: 10.1016/0261-2194(91)90006-D

Loper, J. E., Hassan, K. A., Mavrodi, D. V., Davis, E. W., Lim, C. K., Shaffer, B. T., et al. (2012). Comparative genomics of plant-associated Pseudomonas spp.: insights into diversity and inheritance of traits involved in multitrophic interactions. PLoS Genet. 8:e1002784. doi: 10.1371/journal.pgen.1002784

Luján, A. M., Gómez, P., and Buckling, A. (2015). Siderophore cooperation of the bacterium Pseudomonas fluorescens in soil. Biol. Lett. 11:20140934. doi: 10.1098/rsbl.2014.0934

Marschner, P., Yang, C.-H., Lieberei, R., and Crowley, D. E. (2001). Soil and plant specific effects on bacterial community composition in the rhizosphere. Soil Biol. Biochem. 33, 1437-1445. doi: 10.1016/S0038-0717(01)00052-9

Mavrodi, D. V., Blankenfeldt, W., and Thomashow, L. S. (2006). Phenazine compounds in fluorescent Pseudomonas spp. biosynthesis and regulation. Annu. Rev. Phytopathol. 44, 417-445. doi: 10.1146/annurev.phyto.44. 013106.145710

Mazurier, S., Corberand, T., Lemanceau, P., and Raaijmakers, J. M. (2009). Phenazine antibiotics produced by fluorescent pseudomonads contribute to natural soil suppressiveness to Fusarium wilt. ISME J. 3, 977-991. doi: 10.1038/ismej.2009.33

McSpadden Gardener, B. B., Mavrodi, D. V., Thomashow, L. S., and Weller, D. M. (2001). A rapid polymerase chain reaction-based assay characterizing rhizosphere populations of 2,4-diacetylphloroglucinol-producing bacteria. Phytopathology 91, 44-54. doi: 10.1094/PHYTO.2001.91.1.44

Meyer, J. B., Frapolli, M., Keel, C., and Maurhofer, M. (2011). Pyrroloquinoline quinone biosynthesis gene pqqC, a novel molecular marker for studying the phylogeny and diversity of phosphate-solubilizing pseudomonads. Appl. Environ. Microbiol. 77, 7345-7354. doi: 10.1128/AEM.05434-11

Meyer, J. B., Lutz, M. P., Frapolli, M., Péchy-Tarr, M., Rochat, L., Keel, C., et al. (2010). Interplay between wheat cultivars, biocontrol pseudomonads, and soil. Appl. Environ. Microbiol. 76, 6196-6204. doi: 10.1128/AEM.00752-10

Mirza, M. S., Mehnaz, S., Normand, P., Prigent-Combaret, C., Moënne-Loccoz, Y., Bally, R., et al. (2006). Molecular characterization and PCR detection of a nitrogen-fixing Pseudomonas strain promoting rice growth. Biol. Fertil. Soils 43, 163-170. doi: 10.1007/s00374-006-0074-9

Mulet, M., Lalucat, J., and García-Valdés, E. (2010). DNA sequence-based analysis of the Pseudomonas species. Environ. Microbiol. 12, 1513-1530. doi: 10.1111/j.1462-2920.2010.02181.x

Münkemüller, T., Lavergne, S., Bzeznik, B., Dray, S., Jombart, T., Schiffers, K., et al. (2012). How to measure and test phylogenetic signal. Methods Ecol. Evol. 3, 743-756. doi: 10.1111/j.2041-210X.2012.00196.x

Naik, P. R., Raman, G., Narayanan, K. B., and Sakthivel, N. (2008a). Assessment of genetic and functional diversity of phosphate solubilizing fluorescent pseudomonads isolated from rhizospheric soil. BMC Microbiol. 8:230. doi: 10.1186/1471-2180-8-230

Naik, P. R., Sahoo, N., Goswami, D., Ayyadurai, N., and Sakthivel, N. (2008b). Genetic and functional diversity among fluorescent pseudomonads isolated from the rhizosphere of banana. Microb. Ecol. 56, 492-504. doi: 10.1007/s00248008-9368-9

Oberhänsli, T., Défago, G., and Haas, D. (1991). Indole-3-acetic acid (IAA) synthesis in the biocontrol strain CHA0 of Pseudomonas fluorescens: role of tryptophan side chain oxidase. J. Gen. Microbiol. 137, 2273-2279. doi: 10.1099/00221287-137-10-2273

O'Sullivan, D. J., and O'Gara, F. (1992). Traits of fluorescent Pseudomonas spp. involved in suppression of plant root pathogens. Microbiol. Rev. 56, 662-676.

Picard, C., and Bosco, M. (2005). Maize heterosis affects the structure and dynamics of indigenous rhizospheric auxins-producing Pseudomonas populations. FEMS Microbiol. Ecol. 53, 349-357. doi: 10.1016/j.femsec.2005.01.007

Picard, C., Frascaroli, E., and Bosco, M. (2004). Frequency and biodiversity of 2,4diacetylphloroglucinol-producing rhizobacteria are differentially affected by the genotype of two maize inbred lines and their hybrid. FEMS Microbiol. Ecol. 49, 207-215. doi: 10.1016/j.femsec.2004.03.016

Poly, F., Monrozier, L. J., and Bally, R. (2001). Improvement in the RFLP procedure for studying the diversity of nifH genes in communities of nitrogen fixers in soil. Res. Microbiol. 152, 95-103. doi: 10.1016/S0923-2508(00)01172-4

Prigent-Combaret, C., Blaha, D., Pothier, J. F., Vial, L., Poirier, M.-A., WisniewskiDyé, F., et al. (2008). Physical organization and phylogenetic analysis of $a c d R$ as leucine-responsive regulator of the 1-aminocyclopropane-1-carboxylate deaminase gene acdS in phytobeneficial Azospirillum lipoferum $4 \mathrm{~B}$ and other Proteobacteria. FEMS Microbiol. Ecol. 65, 202-219. doi: 10.1111/j.15746941.2008.00474.x 
Raaijmakers, J. M., de Bruijn, I., and de Kock, M. J. D. (2006). Cyclic lipopeptide production by plant-associated Pseudomonas spp.: diversity, activity, biosynthesis, and regulation. Mol. Plant Microbe Interact. 19, 699-710. doi: 10.1094/MPMI-19-0699

Rameshkumar, N., Ayyadurai, N., Kayalvizhi, N., and Gunasekaran, P. (2012). Genotypic and phenotypic diversity of PGPR fluorescent pseudomonads isolated from the rhizosphere of sugarcane (Saccharum officinarum L.). J. Microbiol. Biotechnol. 22, 13-24. doi: 10.4014/jmb.1107.07025

Ramette, A., Moënne-Loccoz, Y., and Défago, G. (2003). Prevalence of fluorescent pseudomonads producing antifungal phloroglucinols and/or hydrogen cyanide in soils naturally suppressive or conducive to tobacco black root rot. FEMS Microbiol. Ecol. 44, 35-43. doi: 10.1111/j.1574-6941.2003.tb01088.x

Ramette, A., Moënne-Loccoz, Y., and Défago, G. (2006). Genetic diversity and biocontrol potential of fluorescent pseudomonads producing phloroglucinols and hydrogen cyanide from Swiss soils naturally suppressive or conducive to Thielaviopsis basicola-mediated black root rot of tobacco. FEMS Microbiol. Ecol. 55, 369-381. doi: 10.1111/j.1574-6941.2005.00052.x

Rana, A., Saharan, B., Joshi, M., Prasanna, R., Kumar, K., and Nain, L. (2011). Identification of multi-trait PGPR isolates and evaluating their potential as inoculants for wheat. Ann. Microbiol. 61, 893-900. doi: 10.1007/s13213-0110211-z

Rice, O., Miller, S. H., Morrissey, J. P., and O'Gara, F. (2011). Exploitation of glucose catabolic gene fusions to investigate in situ expression during Pseudomonas-plant interactions. Biol. Fertil. Soils 48, 235-238. doi: 10.1007/s00374-011-0586-9

Richardson, A. E., Barea, J.-M., McNeill, A. M., and Prigent-Combaret, C. (2009). Acquisition of phosphorus and nitrogen in the rhizosphere and plant growth promotion by microorganisms. Plant Soil 321, 305-339. doi: 10.1007/s11104009-9895-2

Sarma, R. K., Gogoi, A., Dehury, B., Debnath, R., Bora, T. C., and Saikia, R. (2014). Community profiling of culturable fluorescent pseudomonads in the rhizosphere of green gram (Vigna radiata L.). PLoS ONE 9:e108378. doi: 10.1371/journal.pone.0108378

Simon, A., and Ridge, E. H. (1974). The use of ampicillin in a simplified selective medium for the isolation of fluorescent pseudomonads. J. Appl. Bacteriol. 37, 459-460. doi: 10.1111/j.1365-2672.1974.tb00464.x

Simon, S., and Petrášek, J. (2011). Why plants need more than one type of auxin. Plant Sci. Int. J. Exp. Plant Biol. 180, 454-460. doi: 10.1016/j.plantsci. 2010.12.007

Spaepen, S., Vanderleyden, J., and Okon, Y. (2009). Chapter 7 Plant growthpromoting actions of rhizobacteria Adv. Bot. Res. 51, 283-320.

Srivastava, R., Khalid, A., Singh, U. S., and Sharma, A. K. (2010). Evaluation of arbuscular mycorrhizal fungus, fluorescent Pseudomonas and Trichoderma harzianum formulation against Fusarium oxysporum f. sp. lycopersici for the management of tomato wilt. Biol. Control 53, 24-31. doi: 10.1016/j.biocontrol.2009.11.012

Szkop, M., and Bielawski, W. (2012). A simple method for simultaneous RP-HPLC determination of indolic compounds related to bacterial biosynthesis of indole3-acetic acid. Antonie Van Leeuwenhoek 103, 683-691. doi: 10.1007/s10482012-9838-4

Thomashow, L. S., and Weller, D. M. (1988). Role of a phenazine antibiotic from Pseudomonas fluorescens in biological control of Gaeumannomyces graminis var. tritici. J. Bacteriol. 170, 3499-3508.

Throbäck, I. N., Enwall, K., Jarvis, Å., and Hallin, S. (2004). Reassessing PCR primers targeting nirS, nirK and nos $Z$ genes for community surveys of denitrifying bacteria with DGGE. FEMS Microbiol. Ecol. 49, 401-417. doi: 10.1016/j.femsec.2004.04.011

Troxler, J., Zala, M., Moënne-Loccoz, Y., Keel, C., and Défago, G. (1997). Predominance of nonculturable cells of the biocontrol strain Pseudomonas fluorescens CHA0 in the surface horizon of large outdoor lysimeters. Appl. Environ. Microbiol. 63, 3776-3782.

Vacheron, J., Combes-Meynet, E., Walker, V., Gouesnard, B., Muller, D., MoënneLoccoz, Y., et al. (2016). Expression on roots and contribution to maize phytostimulation of 1-aminocyclopropane-1-decarboxylate deaminase gene acdS in Pseudomonas fluorescens F113. Plant Soil doi: 10.1007/s11104-0162907-0

Vacheron, J., Desbrosses, G., Bouffaud, M.-L., Touraine, B., Moënne-Loccoz, Y., Muller, D., et al. (2013). Plant growth-promoting rhizobacteria and root system functioning. Front. Plant Sci 4:356. doi: 10.3389/fpls.2013.00356

Vacheron, J., Renoud, S., Muller, D., Babalola, O. O., and Prigent-Combaret, C. (2015). "Alleviation of abiotic and biotic stresses in plants by Azospirillum," in Handbook for Azospirillum, eds F. D. Cassán, Y. Okon, and C. M. Creus (Berlin: Springer International Publishing), 333-365.

Venables, W. N., and Smith, D. M. (2011). The R Development Core Team "Introduction to R," Version 2, 04-13. Vienna: R Development Core Team.

Walker, V., Bertrand, C., Bellvert, F., Moënne-Loccoz, Y., Bally, R., and Comte, G. (2011). Host plant secondary metabolite profiling shows a complex, straindependent response of maize to plant growth-promoting rhizobacteria of the genus Azospirillum. New Phytol. 189, 494-506. doi: 10.1111/j.14698137.2010.03484.x

Walker, V., Couillerot, O., Felten, A. V., Bellvert, F., Jansa, J., Maurhofer, M., et al. (2012). Variation of secondary metabolite levels in maize seedling roots induced by inoculation with Azospirillum, Pseudomonas and Glomus consortium under field conditions. Plant Soil 356, 151-163. doi: 10.1007/s11104-011-0960-2

Wang, C., Knill, E., Glick, B. R., and Défago, G. (2000). Effect of transferring 1-aminocyclopropane-1-carboxylic acid (ACC) deaminase genes into Pseudomonas fluorescens strain CHA0 and its gacA derivative CHA96 on their growth-promoting and disease-suppressive capacities. Can. J. Microbiol. 46, 898-907. doi: 10.1139/w00-071

Weller, D. M. (1988). Biological control of soilborne plant pathogens in the rhizosphere with bacteria. Annu. Rev. Phytopathol. 26, 379-407. doi: 10.1146/ annurev.py.26.090188.002115

Weller, D. M., and Cook, R. J. (1983). Suppression of take-all of wheat by seed treatments with fluorescent pseudomonads. Phytopathology 73, 463-469. doi: 10.1094/Phyto-73-463

Yadav, S., Yadav, S., Kaushik, R., Saxena, A. K., and Arora, D. K. (2014). Genetic and functional diversity of fluorescent Pseudomonas from rhizospheric soils of wheat crop. J. Basic Microbiol. 54, 425-437. doi: 10.1002/jobm.201200384

Conflict of Interest Statement: The authors declare that the research was conducted in the absence of any commercial or financial relationships that could be construed as a potential conflict of interest.

Copyright (C) 2016 Vacheron, Moënne-Loccoz, Dubost, Gonçalves-Martins, Muller and Prigent-Combaret. This is an open-access article distributed under the terms of the Creative Commons Attribution License (CC BY). The use, distribution or reproduction in other forums is permitted, provided the original author(s) or licensor are credited and that the original publication in this journal is cited, in accordance with accepted academic practice. No use, distribution or reproduction is permitted which does not comply with these terms. 